\title{
Revisão de Aegoschema Aurivillius (Coleoptera, Cerambycidae, Lamiinae)
}

\author{
Marcela L. Monné ${ }^{1} \&$ José Ricardo M. Mermudes ${ }^{2}$
}

\begin{abstract}
${ }^{1}$ Museu Nacional, Universidade Federal do Rio de Janeiro. Quinta da Boa Vista, São Cristovão, 20940-040 Rio de Janeiro, Rio de Janeiro, Brasil.

2 Departamento de Zoologia, Universidade do Estado do Rio de Janeiro. Rua São Francisco Xavier 524, sala 516, Maracanã, 20550-900 Rio de Janeiro, Rio de Janeiro, Brasil.
\end{abstract}

\begin{abstract}
Revision of Aegoschema Aurivillius (Coleoptera, Cerambycidae, Lamiinae). Aegoschema Aurivillius, 1923 and its species are redescribed, illustrated and a key to identification is given. Six neotropical species are recognized, of which $A$. migueli sp. nov. is described from Brazil (Mato Grosso).

KEY WORDS. Acanthoderini; Neotropical; new species; taxonomy.
\end{abstract}

RESUMO. Aegoschema Aurivillius, 1923 e suas espécies são redescritas, ilustradas e chave para identificação é fornecida. Seis espécies neotropicais são reconhecidas, das quais A. migueli sp. nov. é descrita do Brasil (Mato Grosso).

PALAVRAS-CHAVE. Acanthoderini; espécie nova; Neotropical; taxonomia.

O gênero Aegoschema Aurivillius, 1923 apresenta cinco espécies que se distribuem na América do Sul (Monné 2005). DeJEAn (1835) foi o primeiro a citar o nome Aegomorphus, sem uma descrição, listando sete espécies em nomina nuda. O nome Aegomorphus não estaria disponível por não satisfazer o artigo 12.2 do ICZN (1999). HALdEMAN (1847) descreveu Aegomorphus para A. decipiens, espécie-tipo por monotipia. White (1855) utilizou o nome Aegomorphus do catálogo de Dejean (1835), listando sete espécies sendo quatro nomina nuda, uma já descrita, $A$. pubicornis (Audinet-Serville, 1835), e duas descritas no trabalho: $A$. moniliferus White, 1855 e A. cultrifer White, 1855. Aegomorphus pubicornis, descrita em Oreodera, é atualmente espécie-tipo de Penaherreraus Roguet, 2004 (= Pycnomorphus Thomson, 1864 non Pycnomorphus Motschulsky, 1858). Aegomorphus cultrifer situa-se hoje em Anisolophia Melzer, 1934, na tribo Acanthocinini. Quando White (1855) utilizou o nome Aegomorphus este já estava ocupado por Aegomorphus Haldeman (1847). Thomson (1860) descreveu Aegomorphus, considerando Dejean o autor do nome genérico, para A. adspersus. Aurivillius (1923) percebeu que o nome Aegomorphus tinha sido utilizado por HaLdeman (1847) e propôs Aegoschema como um novo nome para Aegomorphus sensu Thomson, 1860 non Haldeman, 1847 nec White, 1855, tornando $A$. adspersus espécie-tipo por monotipia. Não considerou WHite (1855) autor de Aegomorphus por não ter descrição genérica. LANE (1938, 1973) descreveu, respectivamente, Aegoschema cinereum do Brasil e A. peruvianum do Peru. Gilmour (1965) transferiu Aegomorphus moniliferus White, 1855 e A. adspersus var. obesus Bates, 1861 para Aegoschema e Monné (1994) deu status de espécie a A. obesum. SAma (1994) abordou o histórico do gênero, ci- tando Aegoschema adspersum como espécie-tipo. Monné (2005) equivocou-se ao assinalar White (1855) como autor de Aegomorphus e de que SAMA (1994) designou Aegoschema adspersum como espécie-tipo de Aegoschema.

O gênero e suas espécies são redescritos, é fornecida chave para identificação e descrita uma nova espécie do Mato Grosso (Brasil). O material examinado pertence ao Muséum National d'Histoire Naturelle, Paris (MNHN) e Museu Nacional, Universidade Federal do Rio de Janeiro, Rio de Janeiro (MNRJ). Considerando a publicação de um catálogo (MonNé 2005), as citações bibliográficas referentes a cada táxon limitam-se à descrição original, à citação de MonNé (2005) e, quando pertinente, são incluídas outras citações. As dimensões são fornecidas em milímetros.

\section{Aegoschema Aurivillius, 1923}

Aegoschema Aurivillius, 1923: 610; Monné, 2005: 165.

Aegomorphus Thomson, 1860: 336 (non Haldeman, 1847 nec

White, 1855).

Espécie-tipo: Aegomorphus adspersus Thomson, 1860 por monotipia.

Corpo alongado. Vértex ligeiramente intumescido. Olhos grosseiramente facetados; lobos oculares superiores tão distantes entre si quanto 1,5 vezes a largura de um lobo; lobos oculares inferiores desenvolvidos, pelo menos duas vezes mais largos que os superiores. Genas curtas e com ápices arredondados. Mandíbulas com borda externa carenada e ápice simples. Palpos maxilares mais longos que os labiais; segmento basal cerca da metade do comprimento do segundo que é subigual 
ao apical e 1/3 mais longo que o terceiro; segundo e terceiro cônicos; apical acuminado. Lábio com mento trapezoidal; palpos com segmento basal cerca de 1/3 do comprimento do seguinte; 2-3 subiguais em comprimento; segundo cônico; o apical acuminado. Tubérculos anteníferos pouco proeminentes. Antenas filiformes, com 11 artículos. Escapo cilíndrico, 1/3 mais curto que o antenômero III; III-XI gradualmente encurtados para o ápice e com cerdas eretas e esparsas na região ventral.

Protórax transverso, a cada lado com um tubérculo mediano rombo. Pronoto com cinco tubérculos rombos, dois a cada lado e um pós-mediano; margem posterior ligeiramente sinuosa e com pontos grossos, bem demarcados e moderadamente densos. Cavidades coxais anteriores arredondadas, angulosas aos lados e fechadas atrás. Processo prosternal cerca de $1 / 3$ do diâmetro da cavidade procoxal. Mesosterno plano. Processo mesosternal tão largo quanto o diâmetro da cavidade mesocoxal. Cavidades mesocoxais fechadas aos lados. Escutelo curto, margem apical arredondada. Élitros cerca de quatro a cinco vezes o comprimento do protórax; lados convergentes para o ápice; pontuação grossa e profunda na metade basal; a cada lado do escutelo, com uma crista no quarto basal (exceto $A$. cinereum). Úmeros arredondados e apenas projetados anteriormente.

Pernas anteriores $1 / 3$ mais curtas que posteriores. Fêmures clavados; tíbias deprimidas, ligeiramente expandidas para o ápice e tão longas quanto fêmures; pro- e mesotíbias com sulco. Esporões tibiais curtos, delgados e subiguais. Protarsômero I ligeiramente mais curto que meso- e metatarsômero I e estes, subiguais em comprimento. Escovas tarsais compactas.

Esternitos I-IV subiguais em comprimento; $V$ gradualmente estreitado para o ápice e cerca de 1/3 mais longo que o anterior.

Dimorfismo sexual. As fêmeas apresentam o corpo ligeiramente mais robusto, com élitros subparalelos aos lados. Pernas pouco mais curtas. Esternito V com sulco mediano longitudinal que alcança o terço apical.

Discussão. Aegoschema assemelha-se a Aegomorphus Haldeman, 1847 pelo protórax transverso e tuberculado aos lados, pelo pronoto com tubérculos, os ápices externos dos élitros freqüentemente com espinho e pelos fêmures clavados. Aegoschema difere de Aegomorphus por apresentar o escapo cilíndrico, o pronoto com cinco tubérculos rombos e os lados do protórax com tubérculos arredondados. Em Aegomorphus o escapo é clavado, o pronoto tem, no máximo, três tubérculos rombos e os tubérculos laterais do protórax são aguçados.

\section{Chave para identificação das espécies de Aegoschema}

1. Pronoto com duas faixas longitudinais de pubescência castanho-escura (espinho manifesto no ápice elitral externo) (Fig. 5). Equador, Guiana Francesa, Brasil (Pará)

A. obesum (Bates, 1861)

1'. Pronoto sem faixas longitudinais de pubescência ............. 2

2. Pronoto com pontos, próximos à margem posterior, com diâmetro semelhante aos da base dos élitros; machos com pilosidade da região ventral do corpo amarelada exceto pro- cesso mesosternal e depressão do disco do metasterno, castanho-escura (Fig. 4). Guiana Francesa, Brasil (Pará) ........ A. moniliferum (White, 1855)

2 '. Pronoto com pontos, próximos à margem posterior, com diâmetro menor que os da base dos élitros; machos com pilosidade unicolor na região ventral do corpo ................ 3

3. Metade apical dos élitros com manchas irregulares de pubescência, castanho-escura ou ferrugínea, ornadas de pontos grossos; protarsômeros, nos machos, com pilosidade

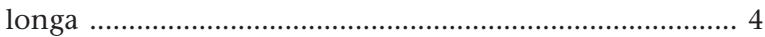

3'. Metade ou terço apical dos élitros sem pontos grossos nas manchas; protarsômeros, nos machos, sem pilosidade lon-

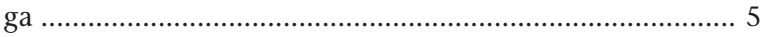

4. Élitros com manchas irregulares de pubescência ferrugínea e sem crista na base; machos com antenômeros III-IV engrossados (Fig. 2). Brasil (Minas Gerais, Espírito Santo) A. cinereum Lane, 1938

4'. Élitros com manchas irregulares de pubescência castanhoescura e, na base, com crista rasa, longitudinal; antenômeros III-IV dos machos não engrossados (Fig. 3). Brasil (Mato Grosso) . A. migueli sp. nov.

5. Pronoto com os tubérculos látero-anteriores mais elevados que os demais; élitros com predominância de pubescência esbranquiçada e manchas irregulares ou máculas de pubescência castanho-escura ou dourada (Fig. 1). Brasil (Bahia, Espírito Santo, Rio de Janeiro, São Paulo)

A. adspersum (Thomson, 1860)

5 '. Pronoto com os cinco tubérculos pouco proeminentes; élitros com predominância de pubescência esverdeada ou acastanhada e manchas irregulares ou máculas de pubescência branca (Fig. 6). Brasil (Amazonas), Peru

A. peruvianum Lane, 1973

\section{Aegoschema adspersum (Thomson, 1860)}

\section{Fig. 1}

Aegomorphus adspersus Thomson, 1860: 337.

Aegoschema adspersum; Lane, 1938: 109; Monné, 2005: 166. Aegoschema adspersa; Gilmour, 1965: 607.

Macho. Tegumento castanho-avermelhado a castanhoescuro. Região ventral com pilosidade amarelada. Região dorsal com pubescência esbranquiçada; ápice dos antenômeros III-XI e tubérculos do pronoto com pubescência castanho-escura; élitros com manchas irregulares e máculas,, de pubescência castanho-escura a dourada concentradas na metade apical; dorso dos fêmures e metade anterior e terço apical das tíbias com mancha de pubescência castanho-escura.

Antenas ultrapassam os ápices elitrais no antenômero IX ou X; escapo estreitado na base e no ápice. Pronoto com um par de tubérculos, próximos à margem anterior, mais elevados que os demais; pontos, próximos à margem posterior, com diâmetro menor que os dos élitros. Processo prosternal, mesosternal e disco do metasterno com pilosidade densa, ereta e concolor 

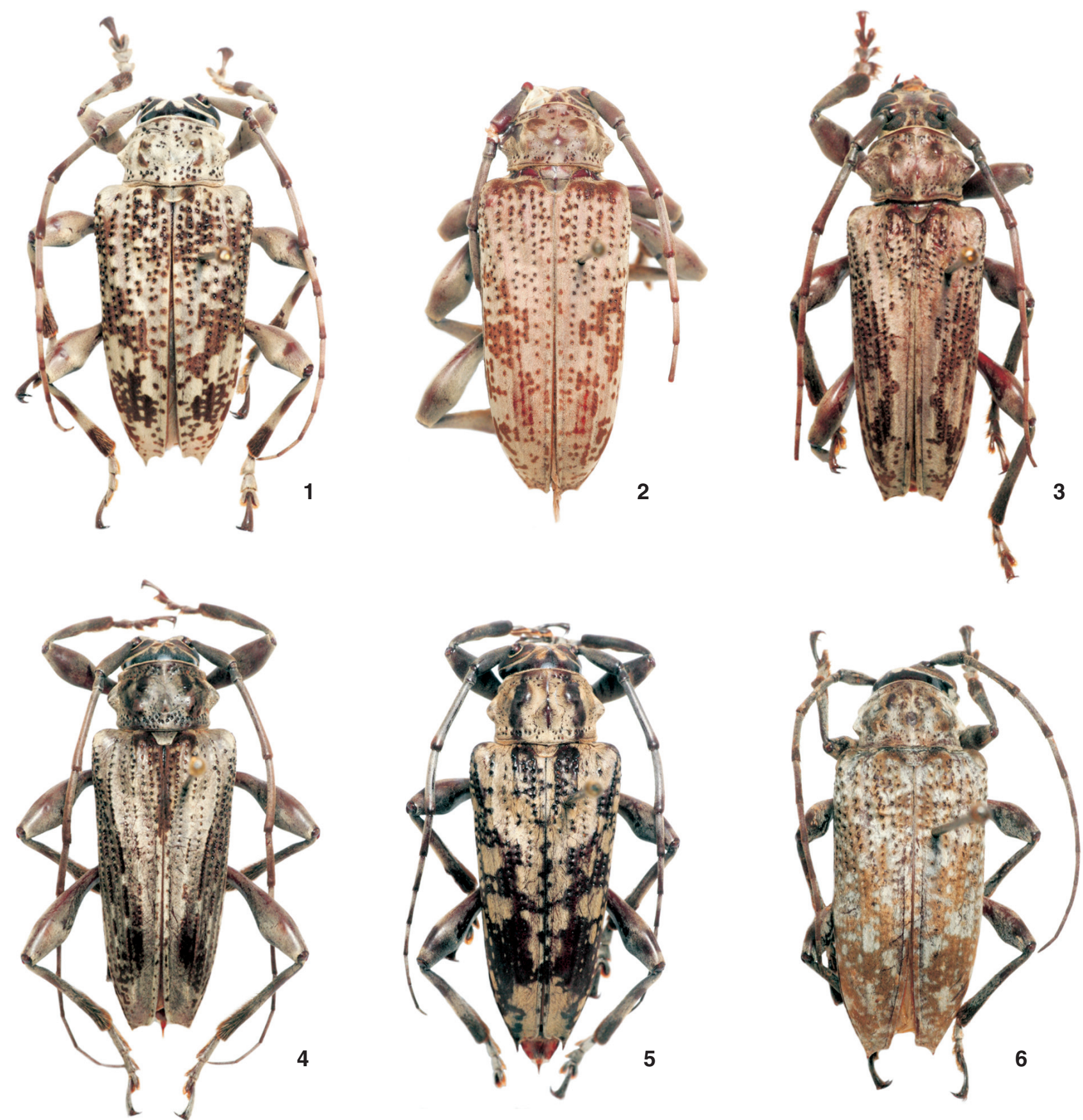

Figuras 1-6. (1) Aegoschema adspersum, macho, 20,2 mm; (2) A. cinereum, holótipo fêmea, 26,2 mm; (3) A. migueli sp. nov., holótipo macho, 23,5 mm; (4) A. moniliferum, macho, 22,5 mm; (5) A. obesum, macho, 21,8 mm; (6) A. peruvianum, holótipo fêmea, 16,5 mm.

com a pubescência do corpo. Disco do metasterno deprimido. Metade basal dos élitros com pontuação densa e moderadamente organizada em fileiras longitudinais; crista basal pouco evidente; ápices obliquamente truncados e com ângulo exter- no espiniforme. Protarsômeros sem pilosidade longa. Esternito $\mathrm{V}$ com margem apical arredondada.

Fêmea. Antenas quase alcançam os ápices elitrais. Processo prosternal, mesosternal e disco do metasterno sem 
pilosidade densa e ereta. Metasterno aplanado. Esternito V com margem apical truncada.

Dimensões, respectivamente macho/fêmea. Comprimento total, 16,5-21,8/16,3-23,8; comprimento do protórax, 2,5-3,8/ 2,4-3,8; maior largura do protórax, 4,5-6,8/4,7-8,2; comprimento do élitro, 11,8-16,2/11,2-18,3; largura umeral, 5,8-9,7/6,0-10,2.

Distribuição geográfica. Ocorre no Brasil, na Mata Atlântica (Bahia, Espírito Santo, Rio de Janeiro, São Paulo).

Material examinado. BrasIL, macho (holótipo) (MNHN); Bahia: Encruzilhada, Estrada Rio-Bahia, km 965, 960 m (Motel da Divisa), 2 machos, 3 fêmeas, XI.1972, Seabra \& Roppa leg.; macho, 3 fêmeas, XI.1974 (sem coletor). Espírito Santo: Colatina, macho, III.1972, F.M. Oliveira leg.; Barra do São Francisco, Córrego do Itá, macho, XI.1956, W. Grossmann leg.; Linhares, Parque Sooretama, 2 machos, 3 fêmeas, XI.1967, F.M. Oliveira leg.; Tijuco Preto, fêmea, 1940. Rio de Janeiro: Rio de Janeiro (Corcovado), macho, 15.XII.1958, fêmea, III.1960, fêmea, XI.1961, fêmea, 31.XII.1962, fêmea, 13.V.1964, Alvarenga \& Seabra leg. São Paulo: Peruíbe, macho, XII.1940, coleção H. Zellibor (todos no MNRJ).

Discussão. Aegoschema adspersum difere, de maneira geral, das demais espécies do gênero pela pubescência esbranquiçada dos élitros com manchas e máculas castanho-escuras a douradas.

\section{Aegoschema cinereum Lane, 1938}

Fig. 2

Aegoschema cinereum Lane, 1938: 108; Monné, 2005: 166.

Macho. Tegumento avermelhado. Corpo com pubescência esbranquiçada ou acinzentada; terço apical dos antenômeros III-XI com pubescência castanha; tubérculos do pronoto, região basal, máculas e manchas irregulares medianas e posteriores dos élitros com pubescência ferrugínea; terço apical das tíbias com pubescência castanho-escura.

Antenas alcançam os ápices elitrais; escapo não estreitado na base; antenômeros III-IV engrossados. Pronoto com um par de tubérculos, próximos à margem anterior, pouco mais elevados que os demais; pontos, próximos à margem posterior, com diâmetro menor que os dos élitros. Processo prosternal, mesosternal e disco do metasterno com pilosidade densa, ereta e concolor com a pubescência do corpo. Disco do metasterno deprimido. Metade basal dos élitros com pontos esparsos, organizados em fileiras longitudinais e adensados aos lados; metade apical com pontos esparsos que acompanham as manchas de pubescência ferrugínea; cristas basais ausentes; ápices obliquamente truncados, ápice externo curto e sem espinho. Protarsômeros com pêlos longos, densos e castanhos. Esternito $\mathrm{V}$ com margem apical truncada.

Fêmea. Antenas apenas alcançam o terço apical dos élitros. Antenômeros III-IV delgados. Processo prosternal, mesosternal e disco do metasterno sem pilosidade densa e ereta. Metasterno aplanado. Esternito V com margem apical sinuosa.

Dimensões, respectivamente macho/fêmea. Comprimento total, 24,0/26,2-29,3; comprimento do protórax, 3,4/3,9-4,3; maior largura do protórax, 7,2/7,3-9,2; comprimento do élitro, 20,0/20,4-23,2; largura umeral, 8,5/8,6-11,8.

Distribuição geográfica. Ocorre no Brasil, na Mata Atlântica (Minas Gerais, Espírito Santo).

Material examinado. BrasiL, Minas Gerais: Manhumirim, fêmea (holótipo), 30.III.1937. Espírito Santo: Jetibá, 800m, 2 fêmeas, X.1960; Tijuco Preto, macho, 1940 (todos no MNRJ).

Discussão. Aegoschema cinereum difere das demais espécies de Aegoschema, pelas características descritas na chave.

\section{Aegoschema migueli sp. nov.}

\section{Fig. 3}

Etimologia. Homenagem ao Prof. Miguel A. Monné (MNRJ), pelo incentivo no estudo dos Lamiinae.

Tegumento castanho-avermelhado. Região dorsal com pubescência esbranquiçada ou acinzentada e ventral, amarelada; pubescência castanho-escura nos tubérculos do pronoto e nos élitros, ao redor do escutelo e formando manchas irregulares nos 2/3 apicais; terço apical das tíbias com pubescência castanho-escura.

Antenas apenas ultrapassam os ápices elitrais; escapo ligeiramente deprimido próximo à base. Pronoto com um par de tubérculos, próximos à margem anterior, distintamente mais elevados que os demais; pontos, próximos à margem posterior, com diâmetro menor que os dos élitros. Processo prosternal e mesosternal com pilosidade densa, ereta e amarelada. Disco do metasterno aplanado. Élitros, na região ao redor do escutelo, com pontos esparsos e enfileirados, adensados nos lados e na região mediana;metade apical com pontos que acompanham as manchas irregulares de pubescência; crista basal baixa; ápices obliquamente truncados com ângulo externo mais longo que o interno e projetado. Protarsômeros com pêlos longos, densos e castanhos. Esternito V com margem apical truncada.

Fêmea. Antenas quase alcançam o ápice dos élitros. Processo prosternal, mesosternal e disco do metasterno sem pilosidade densa e ereta. Esternito $\mathrm{V}$ com margem apical truncada e pequena reentrância mediana.

Dimensões, respectivamente macho/fêmea. Comprimento total, 23,5/25,0; comprimento do protórax, 3,5/3,6; maior largura do protórax, 7,8/7,2; comprimento do élitro, 16,0/19,8; largura umeral, 8,5/9,0.

Distribuição geográfica. Ocorre no Brasil, na floresta Amazônica (Mato Grosso).

Material-tipo. Holótipo macho, BRASIL, Mato Grosso: Sinop, $12^{\circ} 31^{\prime} \mathrm{S}-55^{\circ} 37^{\prime} \mathrm{W}, \mathrm{X} .1974$, Alvarenga \& Roppa leg. Parátipo fêmea, mesmos dados do holótipo (todos no MNRJ).

Discussão. Aegoschema migueli sp. nov. assemelha-se à $A$. cinereum e difere pelas características descritas na chave. Pelo aspecto geral do corpo, assemelha-se também à A. moniliferum e difere, principalmente, por apresentar os élitros apenas com manchas de pubescência castanho-escura. Em A. moniliferum (Fig. 4) os élitros apresentam, além da pubescência castanhoescura, quatro faixas estreitas, longitudinais e descontínuas de 
pubescência branca alternada com castanho-escura. Ver discussão de A. moniliferum.

\section{Aegoschema moniliferum (White, 1855)}

Fig. 4

Aegomorphus moniliferus White, 1855: 374.

Aegoschema monilifera; Gilmour, 1965: 607.

Aegoschema moniliferum; Monné, 1994: 36; 2005: 167.

Macho. Tegumento castanho-avermelhado a castanhoescuro. Região ventral com pilosidade amarelada exceto no processo mesosternal e no metasterno, castanho-escura. Região dorsal com pubescência acinzentada; terço apical dos antenômeros V-XI, tubérculos do pronoto, terço basal da sutura elitral e ao redor do escutelo, com pubescência castanho-escura; élitros com quatro faixas estreitas, longitudinais e descontínuas de pubescência branca alternada com castanho-escura; terço apical das tíbias com pubescência castanho-escura.

Antenas ultrapassam os ápices elitrais no antenômero VIII ou IX; escapo gradualmente estreitado para a base. Pronoto com um par de tubérculos, próximos à margem anterior, distintamente mais elevados que os demais; pontos, próximos à margem posterior, com diâmetro semelhante aos dos élitros. Processo prosternal, mesosternal e disco do metasterno com pilosidade densa, ereta e amarelada. Disco do metasterno deprimido. Élitros, na região ao redor do escutelo, com pontos esparsos e enfileirados e abruptamente adensados aos lados; metade apical lisa; crista basal elevada e evidente; ápices obliquamente truncados. Protarsômeros com pêlos longos, densos e castanhos. Esternito V com margem apical arredondada.

Fêmea. Antenas quase alcançam o ápice dos élitros. Região ventral com pilosidade amarelada. Processo prosternal e mesosternal com pilosidade densa e decumbente. Disco do metasterno aplanado. Esternito V com região circular deprimida, mediana e próxima à margem apical e esta, truncada.

Dimensões, respectivamente macho/fêmea. Comprimento total, 14,2-24,4/14,3-23,2; comprimento do protórax, 2,1-4,0/ 2,2-3,8; maior largura do protórax, 4,5-7,0/4,6-7,7; comprimento do élitro, 10,3-18,2/11,2-18,3; largura umeral, 4,8-8,5/4,9-8,2.

Distribuição geográfica. Ocorre na Guiana Francesa, Peru, Brasil (Amazonas, Pará, Rondônia, Mato Grosso, Goiás) e, possivelmente, relacionada à Floresta Amazônica e nas matas de galeria.

Material examinado. GuiAna Francesa, Montjoly, macho, 18. XI.1982, S. Xiberras leg. BRASIL, Amazonas: Rio Javari, fêmea, X.1958, F.M. Oliveira leg.; Pará: Belém, fêmea, II.1976; Ilha Pará, Igarapé Juntinta, macho, XI.1995, Magno \& C. Alvarenga leg.; Rondônia: Vilhena, macho, XI.1973, Alvarenga \& Roppa leg.; Mato Grosso: Diamantino, fêmea, XI.1971, S.A. Fragoso leg.; Rosário Oeste, macho, XII.1959; Sinop, $12^{\circ} 31^{\prime} \mathrm{S} 55^{\circ} 37^{\prime} \mathrm{W}, 5$ machos, 3 fêmeas, X.1974, Alvarenga \& Roppa leg.; 2 machos, X.1975, Roppa \& Alvarenga leg.; Goiás: Jataí, fêmea, X.1972, F.M. Oliveira leg. Peru, Loreto: Pucallpa, fêmea, 10.IX.1950, H. Zellibor leg. (todos no MNRJ).
Discussão. Aegoschema moniliferum difere das demais espécies do gênero pelas características descritas na chave; as fêmeas são as únicas que apresentam esternito V com região circular deprimida, mediana e próxima à margem apical.

\section{Aegoschema obesum (Bates, 1861)}

Fig. 5

Aegomorphus obesus Bates, 1861: 150.

Aegomorphus adspersus var. obesus; Gemminger \& Harold, 1873: 3141.

Aegoschema adspersa var. obesus; Gilmour, 1965: 607.

Aegoschema obesum; Monné, 1994: 37; 2005: 167.

Macho. Tegumento castanho-avermelhado a preto. Corpo com pubescência esbranquiçada ou amarelada exceto antenas e pernas, acinzentada; terço apical dos antenômeros III-XI, duas faixas longitudinais no pronoto, manchas irregulares nos élitros, mancha no dorso dos fêmures e terço apical das tíbias, com pubescência castanho-escura.

Antenas apenas alcançam ou ultrapassam os ápices elitrais no antenômero X; escapo atenuado na base e no ápice e com depressão dorsal rasa no terço basal. Pronoto com tubérculos semelhantes em elevação; pontos, próximos à margem posterior, com diâmetro menor que os dos élitros. Processo prosternal, mesosternal e disco do metasterno com pilosidade densa, ereta e amarelada. Disco do metasterno deprimido. Terço basal dos élitros com pontos esparsos, enfileirados e gradualmente adensados aos lados; crista basal moderadamente elevada; ápices sinuosos e com espinho desenvolvido no ângulo externo. Protarsômeros sem pêlos longos e densos. Esternito V com margem apical sinuosa.

Fêmea. Antenas quase alcançam o terço ou o quarto apical dos élitros. Processo prosternal, mesosternal e disco do metasterno com pilosidade densa e decumbente. Metasterno aplanado. Esternito V com margem apical truncada e com entalhe mediano.

Dimensões, respectivamente macho/fêmea. Comprimento total, 17,2-22,2/18,5-27,2; comprimento do protórax, 2,8-4,3/ 3,0-4,2; maior largura do protórax, 4,5-7,1/5,2-8,7; comprimento do élitro, 13,3-16,8/14,8-21,3; largura umeral, 5,2-8,5/6,5-10,5.

Distribuição geográfica. Ocorre no Equador, Guiana Francesa, Brasil (Pará, Rondônia, Mato Grosso) e, provavelmente, está relacionada com a Floresta Amazônica.

Material examinado. Brasil, Amazonas: Tabatinga, 2 fêmeas, macho, X.1956, F.M. Oliveira leg.; 2 machos, XII.1956, fêmea, macho, XI.1958, E.S. Lima leg.; Pará: fêmea (holótipo) (MNHN); Óbidos, macho, XII.1955, F.M. Oliveira leg.; Rondônia: Pimenta Bueno, macho, X.1986, Roppa, Magno \& Becker leg.; Vilhena, fêmea, XI.1973, Alvarenga \& Roppa leg.; Mato Grosso: Diamantino, fêmea, XI.1971, S.A. Fragoso leg.; Sinop, 12³1'S $55^{\circ} 37^{\prime} \mathrm{W}, 4$ machos, 3 fêmeas, X.1974, Alvarenga \& Roppa leg.; 2 machos, X.1975, Roppa \& Alvarenga leg. (todos no MNRJ).

Discussão. Aegoschema obesum é a única espécie do gênero com duas faixas de pubescência castanho-escura no pronoto e espinho manifesto no ápice externo elitral. 


\section{Aegoschema peruvianum Lane, 1973}

\section{Fig. 6}

Aegoschema peruvianum Lane, 1973: 394; Monné, 2005: 167.

Macho. Tegumento castanho-avermelhado a castanhoescuro. Cabeça com pubescência esverdeada exceto ao redor dos olhos, esbranquiçada; antenas e pronoto com pubescência acinzentada exceto terço apical dos antenômeros III-XI e tubérculos do pronoto com pubescência castanha; élitros com pubescência esverdeada ou acastanhada exceto manchas irregulares ou máculas de pubescência branca; pernas com pubescência acinzentada exceto mancha no dorso dos fêmures e terço apical das tíbias, castanho-escura. Região ventral com pubescência amarelada.

Antenas ultrapassam os ápices elitrais no antenômero XI; escapo gradualmente estreitado para a base. Pronoto com tubérculos pouco proeminentes; pontos, próximos à margem posterior, com diâmetro menor que os dos élitros. Processo prosternal, mesosternal e disco do metasterno com pilosidade densa, ereta e amarelada. Disco do metasterno deprimido. Terço basal dos élitros com pontos moderadamente densos, enfileirados e bem aparentes; crista basal rasa; ápices obliquamente truncados, ápice interno mais curto que o externo e este ligeiramente projetado. Protarsômeros sem pêlos longos. Esternito V com margem apical arredondada e com leve reentrância mediana.

Fêmea. Antenas alcançam o terço apical dos élitros. Disco do metasterno aplanado e sem pilosidade ereta. Esternito V com margem apical truncada.

Dimensões, respectivamente macho/fêmea. Comprimento total, 17,2/14,3-16,5; comprimento do protórax, 3,1/3,0-3,2; maior largura do protórax, 5,5/4,8-5,0; comprimento do élitro, 12,5/10,5-12,2; largura umeral, 6,5/6,2-6,4.

Distribuição geográfica. Ocorre na Guiana Francesa, Peru, Brasil (Amazonas) e está relacionada à Floresta Amazônica.

Material examinado. BRAsil, Amazonas: Manaus, macho (parátipo), IV.1958, C. Elias leg.; fêmea (parátipo), XI.1958, C. Elias leg.; fêmea, 7.XI.1957, C. Elias leg. Peru, Junin: Satipo, fêmea (holótipo), 1940, A. Maller leg. (MNRJ).

Discussão. Difere das demais espécies do gênero pelas características descritas na chave.

\section{AGRADECIMENTOS}

Ao Conselho Nacional de Desenvolvimento Científico e Tecnológico pelo auxílio concedido (processo: 454591/2006-3).

\section{REFERÊNCIAS BIBLIOGRÁFICAS}

Aurivillius, C. 1923. Neue oder wenig bekannte Coleoptera Longicornia. 19. Arkiv för Zoologi 15 (25): 437-479.

BATES, H.W. 1861. Contributions to an insect fauna of the Amazon Valley. Coleoptera: Longicornes. The Annals and Magazine of Natural History 8 (3): 147-152.

Dejean, P.F.M.A. 1835. Catalogue des Coléoptères de la collection de M. le comte Dejean. Crevot, Paris, 2 ed., 257360 .

Gemminger, M. \& E. Harold. 1873. Catalogus Coleopterorum hucusque descriptorum synonymicus et systematicus. Gummi, Monachii, vol. 10, p. 2989-3232.

Gilmour, E.F. 1965. Catalogue des Lamiaires du Monde (Col., Cerambycidae). Museum G. Frey, Tutzing bei München, p. 559-655.

Haldeman, S.S. 1847. Material towards a history of the Coleoptera Longicornia of the United States. Transactions of the American Philosophical Society 10: 27-66.

IczN. 1999. International Code of Zoological Nomenclature, fourth edition, adopted by the International Union of Biological Sciences. London, International Trust for Zoological Nomenclature, 306p.

LANE, F. 1938. Notas sôbre Lamiideos neotrópicos e descrição de espécies novas (Col., Lamiidae). II. Boletim Biológico 3 (3-4): 107-112.

LANE, F. 1973. Cerambycoidea Neotropica nova IX (Coleoptera). Studia Entomologica 16 (1-4): 371-438.

Monné, M.A. 1994. Catalogue of the Cerambycidae (Coleoptera) of the Western Hemisphere. Part XVII. Subfamily Lamiinae: Tribes Anisocerini, Polyrhaphidini, Xenofreini, Acrocinini and Acanthoderini. São Paulo, Sociedade Brasileira de Entomologia, 110p.

Monné, M.A. 2005. Catalogue of the Cerambycidae (Coleoptera) of the Neotropical Region. Part II. Subfamily Lamiinae. Zootaxa 1023: 1-759.

SAMA, G. 1994. Note sulla nomenclatura dei Cerambycidae della regione mediterranea. II. Revisione di alcuni tipi de Kraatz, v. Heyden e Stierlin. Lambillionea 94 (3): 321-334.

Thomson, J. 1860. Essai d'une classification de la famille des cérambycides et matériaux pour servir a une monographie de cette famille. Paris, Bouchard-Huzard, 404p.

White, A. 1855. Catalogue of the coleopterous insects in the collection of the British Museum. Longicornia 2. London, British Museum, vol. 8, p. 175-412.

Recebido em 16.II.2007; aceito em 04.VII.2007. 